\title{
A study on Food Security of Rural Households in Iran and Its Effective Socioeconomic Factors
}

\author{
Alireza Rahbar Dehghan ${ }^{1}$, Hossein Mehrabi Boshrabadi ${ }^{2 *}$, Seyyed Abdolmajid Jalaee Esfandabadi ${ }^{3}$ \\ 1- Ph.D. Candidate of Agricultural Economy, Shahid Bahonar University of kerman, Kerman, Iran \\ 2- Professor, Department of Agricultural Economy, Shahid Bahonar University of kerman, Kerman, Iran \\ 3- Professor, Department of Economy, Shahid Bahonar University of kerman, Kerman, Iran
}

\section{A B S T R A C T}

Background and Objectives: Population growth and increased food requirements of humans have increased demands for agricultural foods. Indeed, food security is the foundation of a developed society and constitutes the major component of health, efficiency and learning. Based on the role of food security in human health and development, objective of the present study was to investigate statuses of food security in rural households of Iran and socioeconomic factors affecting these statutes.

Materials and Methods: Food security statuses of 19267 rural households were first assessed using income-expense questionnaires, 2018, and method of determining optimal food basket for the Iranian society based on the energy recommended by the Community Nutrition Department, Ministry of Health and Medical Education of Iran. Factors affecting food security were assessed using logit model.

Results: Results of the food security index showed that rural households of Iran were generally at intermediate levels since the food security index values were higher than those of average in $53.12 \%$ of the rural households and lower than those of average in $46.88 \%$ of them. It was shown by the logit model that farm income, non-farm income, age, gender, educational level, employment status and house ownership status of household heads included significant positive effects on food security of the households. Moreover, family size and marital status of the household heads included negative effects on food security.

Conclusions: Although food security status of the Iranian rural families is relatively moderate, increasing nutritional knowledge and providing employment opportunities to increase incomes and purchase powers of optimal food baskets can be effective in improving food security.

Keywords: Food security, Logit model, Rural households, Socioeconomic factors, Iran

\section{Introduction}

Roles of nutrition in people health, efficiency and learning and its links with economic development have been well-established by extensive studies worldwide $(1,2$, $3,4,5)$. The concept of food security originates from the global food crisis of early 1970s, first emerged in 1974 World Food Conference (6). Based on a definition in 1996 Global Food Summit, food security includes physical, economic and social access of all people at any time to adequate, safe and nutritious foods that they can satisfy their nutritional needs and food preferences for a healthy and active life $(7,8,5)$. Surveys on statuses of food security in 2017 revealed that despite progresses in economic growth of several developing countries, nearly
821 million people of world suffered from hunger and insecurity. Furthermore, at least $70 \%$ of the total poor population of world reside in rural areas. Studies on food security suggest that food insecurity is a major challenge in most nations and is linked to food intakes and nutritional, economic, social and cultural statuses $(9,10)$. It has been reported that economic and income factors play key roles in food security and the potential ability of households in satisfying their needs. Moreover, cultural and social factors include essential roles in effective management of household budgets as well as selection of foods at affordable prices (11). Based on the significance of food security in rural and agricultural development programs in 
Iran, the aim of the present study was to investigate statuses of food security in rural households of Iran and its effective socioeconomic factors. Findings can greatly help health policymakers and contribute to human development and eventually rural development. Therefore, the study tried to answer questions of how much food security is frequent in rural households in various provinces of Iran and if relationships exist between the statuses of food security in rural households and its socioeconomic factors.

\section{Materials and Methods}

The present study was an applied study in terms of goals and a cross-sectional descriptive-analytical study in terms of how information were accessed. Food security of the rural households was assessed using table of recommended optimal per capita energy-nutrient food baskets, prepared by the National Office of Nutrition Improvement, Ministry of Health and Medical Education of Iran, 2018 (19). A food consumption basket refers to a combination of the main foods that can provide nutrients needed for physical activities and decreasing diseases. An optimal food basket is a pattern that provides adequate and balanced diets and encompasses personal differences, including ages, genders, living neighborhoods, occupations, food preferences, food habits and cultures. This basket should reflect food production and access facilities and socioeconomic conditions of the society. Nutrients are presented in such a pattern in adequate quantities and proportional ratios and hence diseases caused by undernourishment such as protein malnutrition, iron-deficiency anemia and vitamin deficiency decrease. In addition, food balance and diversity are important in the basket to decrease risks of chronic diseases caused by inappropriate nutrition. In fact, an optimal food pattern is based on nutritional adequacy, diversity and balance. According to Table 1, the optimal per capita food consumption of Iranians averagely includes $1563 \mathrm{~g} / \mathrm{d}$, which is equivalent to $2574 \mathrm{kcal} / \mathrm{d}$. In the present study, food security of the Iranian rural households in various provinces was assessed using 19267 rural household income-expense questionnaires in 2018 (19). Therefore, quantities of food intakes from the list of the recommended optimal food basket were extracted from the household income-expense data. Since data represented food consumption of a typical rural family per month, data were divided by 30 days. To convert data to calories (as the household expense and income data were in $\mathrm{kg}$ ), data were multiplied by 1000 (g) (Table 1). Furthermore, calorie intakes from consumption of one gram of foods were calculated for the provinces.
Table 1. The optimal food basket of Iranian households, 2018

\begin{tabular}{llll}
\hline Sr. No. & $\begin{array}{l}\text { Foodstuff/Food } \\
\text { groups }\end{array}$ & $\begin{array}{l}\text { Per capita consumption } \\
(\mathrm{g} / \mathrm{da})\end{array}$ & $\begin{array}{l}\text { Energy } \\
(\mathrm{kcal})\end{array}$ \\
\hline 1 & Rice & 95 & 339 \\
2 & Bread & 310 & 879 \\
3 & Pasta & 20 & 72 \\
4 & Red meat & 38 & 106 \\
5 & White meat & 64 & 82 \\
6 & Dairy & 250 & 207 \\
7 & Egg & 35 & 45 \\
8 & Oil & 35 & 315 \\
9 & Fruit & 280 & 141 \\
10 & Vegetable & 300 & 85 \\
11 & Potato & 70 & 57 \\
12 & Sugar & 40 & 155 \\
13 & Pulse & 26 & 91 \\
14 & Total & 1563 & 2574 \\
\hline
\end{tabular}

Source: National Office of Nutrition Improvement, Ministry of Health and Medical Education of Iran

Based on the optimal food basket by Department of Community Nutrition, Ministry of Health and Medical Education of Iran, every person needs $2574 \mathrm{kcal}$ of energy per day from 13 recommended food groups and intakes of less than $2574 \mathrm{kcal}$ energy cause food insecurity of the household members (Appendix 1). Logit regression and EViews Software v.10 (IHS Markit, USA) were used to investigate relationships between the food security of rural households and socioeconomic factors, including household income, educational level, marital status, age and gender of household head, house ownership status and family size. Structure of the logit model is presented as follows.

\section{Logit model structure}

The logit model was used when dependent variable was not visible. In this condition, dependent variable emerged as a dichotomous choice. Dependent variable included a value of either 0 or 1 , depending on the occurrence or nonoccurrence of phenomenon in the question. Therefore, dependent variable could be used to estimate occurrence or non-occurrence of the intended event.

$P_{i}=F\left(Z_{i}\right)=F\left(\alpha+\beta X_{i}\right)=1 / 1+e^{-Z_{i}}=1 / 1+e^{-\left(\alpha+\beta X_{i}\right)}$

Where, $e$ represented base of the natural logarithm (Napier's constant). Equation (1) expressed what was known as the logistic cumulative distribution function. As $Z_{i}$ varied from $-\infty$ to $+\infty, P_{i}$ included a value of 0 to 1 . 
Since the sum of all probabilities was 1, probability for the $i$ th household with food insecurity was estimated by the following equation:

$1-P_{i}=1 / 1+e^{z_{i}}=1 / 1+e^{\left(\alpha+\beta X_{i}\right)}$

Therefore,

$\frac{P_{i}}{1-P_{i}}=\frac{1+e^{Z_{i}}}{1+e^{-Z_{i}}}=e^{Z_{i}}$

Ratio of the probability of the case to its alternative expressed the superiority of $P_{i} / 1-P_{i}$ as probability of the occurrence of food security to its non-occurrence:

(4)

$L_{i}=\operatorname{Ln} \frac{P_{i}}{1-P_{i}}=\alpha+\beta X_{i}$

Where, $L_{i}$ represented logarithm of the acceptance to non-acceptance in terms of $X$ and linear parameters. Therefore, logit model was used to show the factors affecting food security in rural households of Iran. The model could be expressed as follows:

$$
\begin{aligned}
& Y_{\mathrm{i}}=F\left(Z_{i}\right) \\
& Z_{i}=\alpha+\sum_{J=1}^{N} \beta_{j} X_{i j} \\
& \mathrm{Z}_{\mathrm{i}}=\alpha+\beta_{1} X_{i 1}+\beta_{2} X_{i 2}+\beta_{3} X_{i 3}+\ldots+\beta_{n} X_{i n}+u_{i}
\end{aligned}
$$

$$
\mathrm{Z}_{\mathrm{i}}=\alpha+\sum_{J=1}^{9} \beta_{j} X_{i}+u_{i}
$$

Where, $Y_{i}$ was the qualitative-dependent variable of food security that included the value of 1 for the probability of the presence of food security and the value of 0 for the probability of the lack of food security, $\alpha$ was the $y$ intercept of the model, $n$ was the total number of observations, $\beta_{j}$ was the parameters of the model for estimation, $u_{i}$ was the random error term and $X_{j}$ was the independent (descriptive) variables of the model, including a set of socioeconomic factors that affected food security levels (Table 2). The logit model was estimated using maximum empirical likelihood (MEL) method. Results for the LR statistic (perfectly significant at $1 \%$ levels) indicated that it was improbable for the coefficients of all independent variables to be zero and this further verified that the model was generally significant. Moreover, pairwise correlations of the independent variables were calculated to check the collinearity.

\section{Results}

General statuses of food security showed that Iranian rural households were overall at a moderate level of food security based on the energy intake, 2018. Of the provinces, food security in 18 provinces was higher than average (58.04\% of the rural households), while it was lower than average for other $46.88 \%$ of the rural households. The highest energy intake belonged to provinces of Kermanshah, Markazi and Ardabil and the lowest one belonged to provinces of Kohgiluyeh and Buyerahmad, Tehran and Gilan. These verified that villages in western and northern provinces were highly food secure, but villages in the eastern and southern provinces are lowly food secure.

Table 2. Independent variables of the logit model

\begin{tabular}{llll}
\hline Variable & Definition & \multicolumn{2}{l}{ Value } \\
\cline { 3 - 4 } & & 1 & 0 \\
\hline $\mathrm{X}_{1}$ & Educational level of the household head & Over diploma & Under diploma \\
$\mathrm{X}_{2}$ & House ownership status & Owned & Non-owned \\
$\mathrm{X}_{3}$ & Gender of the household head & Male & Female \\
$\mathrm{X}_{4}$ & Employment status of the household head & Employed & Unemployed \\
$\mathrm{X}_{5}$ & Marital status & Married & Single \\
$\mathrm{X}_{6}$ & Family size & People & \\
$\mathrm{X}_{7}$ & Monthly non-farm income of the household head & (IRR) & \\
$\mathrm{X}_{8}$ & Monthly farm income of the household head & (IRR) & \\
$\mathrm{X}_{9}$ & Age of household head & Year & \\
\hline
\end{tabular}




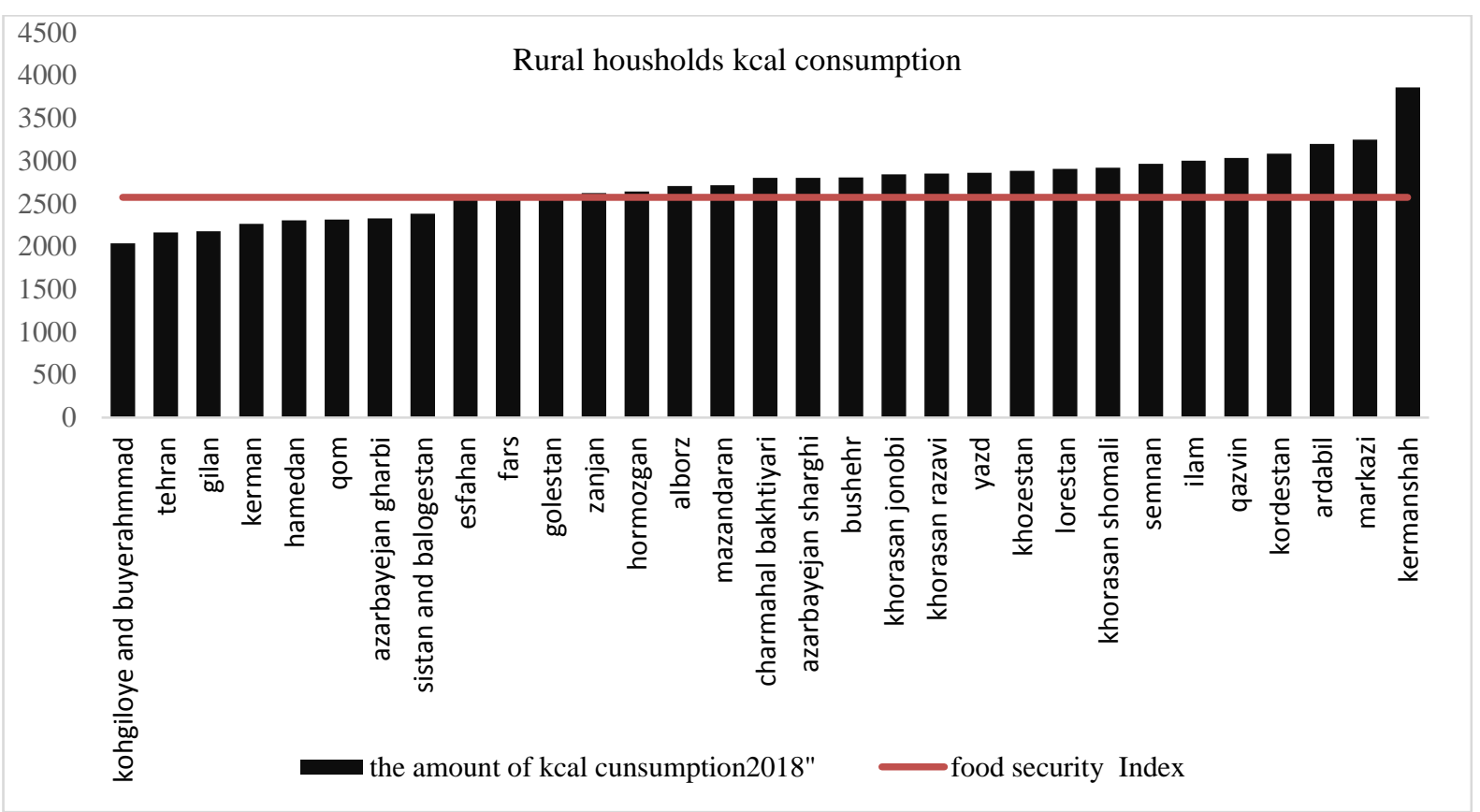

Figure 1. Calories consumed in various provinces of Iran, 2018

To better present results and document them using Geographic Information Systems (GIS) Software, results were reported in Figure 1, demonstrating geographical distribution of the food security index of rural households in Iran, 2018. Results revealed that due to self-subsistence, rural households were more affected by crop production in their own provinces and production rate fluctuations affected their food security profoundly. Therefore, western provinces with better geographical regions of agriculture produced further agricultural supplies with higher incomes. In addition, average cultivated areas were higher in western regions of Iran, which increased the incomes of rural households. Therefore people in these regions included higher potentials for providing the optimal food baskets and thus food security. In recent decades, drought greatly affected water resources in east and south regions of Iran more adversely than the other regions and hence caused further food insecurity in these regions. The northern provinces included relatively small population densities and despite their vast agricultural lands and rainfall, they were in bad situations of food security.

\section{Results of the logit model}

Correlations of the variables were weak with no problems of collinearity. Results of the goodness-of-fit test by Andrews and H-L test revealed that the model was wellfit (Table 3). The index of correctness of the model prediction was $75.12 \%$, verifying that the estimated model was $75.12 \%$ successful in predicting dependent variables correctly. Moreover, these indices reflected that the model was appropriately used in describing behaviors of the variables.

Table 3. Estimation of the logit model using maximum empirical likelihood

\begin{tabular}{lllllll}
\hline Variable & & Coefficient & Standard error & Z-statistic & Probability & Marginal impact of the variable \\
\hline Constant coefficient & $\mathrm{c}$ & $0.1265^{* * *}$ & 0.3806 & 3.3120 & 0.0009 & 0.04581 \\
Educational level of the household head & $\mathrm{X}_{1}$ & $0.020461^{*}$ & 0.010256 & 1.950560 & 0.0558 & 0.0074 \\
House ownership status & $\mathrm{X}_{2}$ & $0.2312^{* * *}$ & 0.1343 & 1.7210 & 0.0852 & 0.0837 \\
Gender of the household head & $\mathrm{X}_{3}$ & $0.2074^{* * *}$ & 0.09718 & 2.1316 & 0.0178 & 0.0751 \\
Employment status of the household head & $\mathrm{X}_{4}$ & $0.5472^{* * *}$ & 0.1444 & 3.7895 & 0.0002 & 0.1981 \\
Marital status & $\mathrm{X}_{5}$ & -0.0807 & 0.1576 & -0.5124 & 0.6083 & $0.0292-$ \\
Family size & $\mathrm{X}_{6}$ & $-0.4892^{* * * *}$ & 0.0220 & -22.1567 & 0.0000 & $0.1771-$ \\
Monthly non-farm income of the household head & $\mathrm{X}_{7}$ & $0.0032^{* *}$ & 0.0012 & 2.6149 & 0.0089 & 0.049 \\
Monthly farm income of the household head & $\mathrm{X}_{8}$ & $0.004561^{* * *}$ & 0.000789 & 5.706 & 0.0000 & 0.073 \\
Age of household head & $\mathrm{X}_{9}$ & $0.008139^{* * *}$ & 0.00211 & 3.8461 & 0.0001 & 0.0029 \\
\hline
\end{tabular}

\section{LR statistic, 866.58}

Prob (LR statistic), 0.000

R-squared, 0.6815

$\%$ correct, $75.12 \%$

Prob (H-L statistic), 0.000

Prob (Andrews), 0.000

***, $1 \%$ confidence level; **, $5 \%$ confidence level; *, $10 \%$ confidence level

Source: Research findings. 


\section{Discussion}

Using logit model, Faridi and Wadood (12) investigated that educational levels, food prices, populations, farm incomes and non-farm incomes were the factors that described food security of Bangladeshi families. According to Gustafson (13), increases in food prices include negative effects on food security of Indian families. Hosseini et al. (5) reported significant positive effects of targeted subside policies on food security of urban households in Iran. Abdullah et al. (14) studied factors that dictated food security of rural households in Pakistan using logistic method and showed that age, gender, education, unemployment, inflation and disease were important factors affecting food insecurity of households. Tiwari et al. (2016) addressed effects of income and cash on food security of African households and reported that the program of Livelihood Empowerment against Poverty could be effective by increasing household revenues and thereby enhancing food security. In a study on American households, Alisha et al. (15) detected that adequate access to foods is necessary for the safe life of all family members. Furthermore, they reported that $27 \%$ of households suffered from food insecurity. Belay Bedeke (16) investigated factors affecting food security in Kersa District, East Ethiopia. Results demonstrated that family size and household head gender (females) included negative relationships with food security. Tsegay (17) assessed food security of rural households in Tigray region of Ethiopia and revealed that $42 \%$ of the families were food insecure and $57 \%$ of them were food secure. In a similar study on food security of households in Nigeria, Omotesho et al. (18) reported that $60 \%$ of families were food insecure and income and age of the family heads included significant positive relationships with food security.In this study, the marginal impact of each variable was estimated to find out how effective each variable was on the food security of rural households. The marginal impact of the variable of income was 0.073 , revealing that if monthly revenue of a household increased by one unit (1 million IRR), the likelihood of food security averagely increased by $0.073 \%$. Positive effects of farm incomes on improving food security have been supported by Abdulai and Aubert (14), Babatunde and Qaim (20), Akerele (21) and Tiwari et al. (22). Educational level was expected to affect food security positively. The higher the educational level was, the higher the food security of the household was. This expectation was linked to the fact that further educated people could use further modern agronomic technologies on their farms and hence improve their productivity, guarantying other job opportunities in the market. In rural regions, further educated household heads included further knowledges of correct principles of nutrition and those with higher educational levels were aware of various food constituents. Therefore, they could improve their quality of life (QOL), have better access to foods and increase their food security. Based on the results in Table 2, the household head educational levels included significant positive effects on the food security index and hence when the educational level increased by one unit, the likelihood of food security of the rural households increased by $0.0074 \%$

Results of the logit model for household head age revealed its significant positive effects on food security at 99\% confidence levels. Therefore, direct relationships existed between the household head age and food security index. The marginal impact of the variable of age was estimated at 0.0029 , showing increases in the likelihood of food security by average $0.0029 \%$. Positive relationships between the household head age and the probability of food security have previously been supported by Ramezani (23), Abdulai and Aubert (24), Aromolaran (25), Migotto et al. (26), Abebaw et al. (27), Akerele (21), Owusu et al. (8) and Anriquez et al. (28). Results of the logit model showed that the household head gender affected food security positively and significantly at $95 \%$ confidence levels. Marginal impact of this variable was 0.0751 , showing an increase of $0.0751 \%$ in the likelihood of food security. Household head gender demonstrated people roles in supplying needs (e.g., foods) of their families. Households whose heads were female had higher dependence relationships, revealing their potentials to assign labors to farm and non-farm income generating activities. In addition, such families were usually older with lower educational levels (FAO, 2014). In the current study, the marginal impact of the household head marital status was 0.0292 with no statistically significant differences. The marginal impact of family size was - 0.1771, showing that higher family sizes decreased the likelihood of food security. This inverse relationship has been verified by Migotto et al. (26), Babatunde and Qaim (20) and Akerele (21). Results have revealed significant positive effects of the monthly incomes of nonfarm activities at $95 \%$ confidence levels, showing direct relationships between the household head monthly revenues and food security index. In the present study, the marginal impact was 0.049 for the variable of income. Therefore, if a family monthly income of non-farm activity increased by one unit (1 IRR), the likelihood of food security increased by $0.049 \%$ averagely. Moreover, variable of house ownership as an indicator of family wealth included positive effects on food security due to the decreases in renting and mortgage costs. Similar findings have been reported by Migotto et al. (26) and Abebaw et al. (27).

\section{Conclusion}

In general, the present study has answered the question of how food security statuses of the Iranian rural 
communities are. To answer the question, food security statuses of rural households were assessed based on the recommended energy and nutrient intakes in the optimal food basket. Furthermore, relationships between the socioeconomic factors and food security were assessed using logistic regression. Results of food security in Iran (2018) showed that the rural households were generally at moderate levels of food security. Rural households in Iran are naturally affected by the crop production of their own provinces to a greater extent due to their self-subsistence. Incomes of farm and non-farm activities are the major key factor in food purchase and consumption at household levels. Except for two variables of family size and marital status of the household heads whose marginal effects on food security of the rural households were negative, other variables of age, gender, educational level, job status and house ownership status of the household heads included significant positive effects on food security. Based on the positive effects of education on food security of the rural households, the government is recommended to monitor formal and informal educational levels of the rural families to motivate them for further educations. In addition, improvement of farm incomes of the rural households can be the most important factor in increasing their food security. Since incomes of the rural households are mostly supplied by farming activities, the government should officially support purchase of crops (guaranteed purchase), distribute farm needs at governmental prices, suggest appropriate cropping patterns, establish crop value chains, prevent financial intermediation of crop purchases, improve crop productivities and build infrastructures for more rapid transportation of crops to markets; thereby, increasing farm revenues of the rural households. Based on the effective roles of off-farm incomes in improvement of the food security of rural households, the government should grant further low-interest loans, found rural microcredit funds and improve financial potential of the rural communities; thereby, supporting rural businesses. Ownership of the rural houses is another variable that can increase food security of the households. Considering increasing costs of the house building materials, the government is recommended to build inexpensive houses in villages.

\section{Financial disclosure}

The authors declared no financial interest.

\section{Funding/Support}

This manuscript is a part of a $\mathrm{PhD}$ dissertation. All the expenses within the current dissertation were paid personally and no financial supports were provided by other organizations.

\section{References}

1. Fengying N, Jieying B, Xuebiao Z. Study on China's food security status.Agriculture and Agricultural Science Procedia .2010.1: 301-310.

2. Renzaho A M, Mellor D. Food security measurement in cultural pluralism: Missing the point or conceptual misunderstanding? . Nutrition. 2010; 26(1): 1-9.

3. Carletto C, Zezza A, Banerjee R. Towards better measurement of household food security: Harmonizing indicators and the role of household surveys. Global.2013.

4. Smith P. Delivering food security without increasing pressure on land. Global Food Security.2013; 2(1): 18-23.

5. Hosseini SS, Pakravan MR, Charvadeh H, Salami A, Flora C. The impact of the targeted subsidies policy on household food security in urban areas in Iran. Cities63. 2017: 110-117.

6. Maxwell S. The evolution of thinking about food security. In S. Devereux, \& S. Maxwell (Eds.), Food Security in SubSaharan Africa. 2001: 13-31.

7. Food and Agriculture Organization of the United Nations (FAO). Rome declaration on world food security and world food summit plan of action, World Food Summit, Rome, Italy. 1996.

8. Owusu V, Abdulai A, Abdul-Rahman S. Non-farm work and food security among farm households in Northern Ghana. Food Policy. 2011; 36(2): 108-118.

9. Studdert LJ, Frongillo EA, Valoist p. Household food insecurity was prevalent in Java during Indonesia's economic crisis. Journal of Nutrition. 2001; 131(70): 2685-91.

10. Ahmad Sh, Siddique Javed M, Ghafoor A. Estimation of Food Security Situation at Household Level in Rural Areas of Punjab. International Journal of Agriculture and Biology. 2004; 6(3): 483-487.

11. Lahteenkorva SS, Lahelma E. Food insecurity is associated with past and present economic disadvantageand body mass index. Journal of Nutrition. 2001; 131(11): 2880-4.

12. Faridi R, Wadood SN. An Econometric Assessment of Household Food Security in Bangladesh, The Bangladesh Development Studies. September 2010; 3(2).

13. Gustafson DJ. Rising Food Costs and Global Food Security: Key Issue and Relevance for India. Indian Journal of Medical Research. 2013; 138 (3): 398- 410.

14. Abdullah Z D, Shah T, Ali S, Ahmad W, Din I.U, Ilyas A. Factors affecting household food security in rural northern hinterland of pakistan. Journal of the Saudi Society of Agricultural Sciences. 2017: 1-34.

15. Alisha C, Matthew P, Rabbitt C A, Gregory A S. Household Food Security in the United States in 2015. Economic Research Service/USDA .2015; Number 215.

16. Belay Bedeke S. Food insecurity and Copping Strategies: a Perspective from Kersa District, East Haraghe Ethopia, food Science and Quality Management, 2012;Vol,5.

17. Tsegay Gebrehiwot Determinants of food security in rural households of the Tigray region. A thesis submitted to Addis Ababa University in partial fulfillment of the requirements for the degree of master of since in applied statistics. 2009. 
18. Omotesho OA. Adewum, M.O, Fadimula K S. Food Security and Poverty of the Rural Households in Kwara State, Nigeria. Libyan Agriculture Research Center Journal International. 2010;1 (1): 56-59.

19. Salehi F, Abdolahi Z, Abdolahi M, Optimal food basket andisheh Mandegar Publications, 2013: 29.

20. Babatunde R O, Qaim M, Impact of off-farm income on food security and nutrition in Nigeria, Food Policy. 2010; 35: 303311.

21. Akerele D, Intra-household food distribution patterns and calorie inadequacy in South-Western Nigeria. journal of Consumer Studies. 2011; 35: 545-551.

22. Tiwari S. Impact of cash transfer programs on food security and nutrition in sub-Saharan Africa: A cross-country analysis. Global Food Security. 2016.http://dx.doi.org/10.1016/j.gfs. 2016.07.009i.

23. Ramezani CA Determinations of Nutrient Demand: A Nonparametric Analysis, Journal of Agricultural and Resource Economics. 1995; 20 (1): 165-177.
24. Abdulai A, Aubert D.Nonparametric and parametric analysis of calorie consumption in Tanzania, Food Policy. 2004; 29:113-129

25. Aromolaran AB. Household income, women_s income share and food calorie intake in South Western Nigeria. Food Policy. 2004; 29: 507-530.

26. Migotto M, Davis B, Carletto G, Beegle K, Measuring Food Security Using Respondents' Perception of Food Consumption Adequacy. ESA Working Paper. 2005: 5-10.

27. Abebaw D, Yibeltal F, Belay K. The impact of a food security program on household food consumption in Northwestern Ethiopia: A matching estimator approach, Food Policy. 2010; $35: 286-293$.

28. Anriquez G, Daidone S, Mane E. Rising food prices and undernourishment: A cross-country inquiry, Food Policy. 2013, 38: 190-202. 